\title{
DYNAMICS OF POST-STROKE HAND PARESIS KINEMATIC PATTERN DURING REHABILITATION
}

Khizhnikova AE $\otimes$, Klochkov AS, Kotov-Smolenskiy AM, Suponeva NA, Piradov MA

Research Center of Neurology, Moscow, Russia

According to the literature data, only $5-20 \%$ of post-stroke patients are able to restore the hand motor function completely. Correct goal setting and individual approach to the patient's functional recovery are important. Our study aimed to develop an algorithm of impaired hand motor functioning assessment for post-stroke patients and to determine the principles of the rehabilitation tactics choosing based on the biomechanical analysis. Twenty five patients with hemispheric stroke and 10 healthy volunteers participated in the study. Formal clinical observation scales (Fugl-Meyer Assessment, Ashworth Scale, ARAT) and video motion analysis were used for evaluation of the hand motor function. Patients were divided into 2 groups according to the hand paresis severity (mild/moderate and pronounced/severe). Rehabilitation was carried out in both groups, including mechanotherapy, massage and physical therapy. It was revealed that in the 1 st group of patients the motor function recovery in the paretic hand was due to movement performance recovery: biomechanical parameters restoration directly correlated with a decrease in the paresis degree according to the Fugl-Meyer Assessment Scale $(r=0.94 ; p=0.01)$. In the 2nd group of patients, the motor function recovery in the paretic hand was due to motor deficit compensation: according to biomechanical analysis, the pathological motor synergies inversely correlated with a decrease in the paresis degree $(r=-0.9 ; p=0.03)$. As a result of the study, an algorithm for selecting the patient management tactics based on the baseline clinical indicators was developed.

Keywords: stroke, hand paresis, neurorehabilitation, adaptation, motor relearning, movement biomechanics, motion capture, abnormal synergy

Funding: the study was performed as a part of the public contract № 0512-2014-0036.

Author contribution: Khizhnikova AE — research planning, literature analysis, data acquisition, analysis and interpretation, manuscript draft writing; Klochkov AS — research planning, literature analysis, data interpretation, manuscript writing; Kotov-Smolenskiy AM — training of surveyed patients, patients examination using clinical scales; Suponeva NA — research planning, data interpretation, manuscript writing; Piradov MA — manuscript writing.

Compliance with ethical standards: the study was approved by the Ethics Committee of Research Center of Neurology (protocol № 5/16 dated January 27, 2016). All enrolled patients signed informed consent to participation in the study.

$\triangle$ Correspondence should be addressed: Anastasia E. Khizhnikova Volokolamskoye Shosse 80, Moscow, 125367; nastushkapal@gmail.com

Received: 16.08.2019 Accepted: 30.08.2019 Published online: 31.08.2019

DOI: $10.24075 /$ brsmu.2019.056

\section{ДИНАМИКА КИНЕМАТИЧЕСКОГО ПОРТРЕТА ПОСТИНСУЛЬТНОГО ПАРЕЗА РУКИ НА ФОНЕ РЕАБИЛИТАЦИИ}

\author{
А. Е. Хижникова $\bowtie$, А. С. Клочков, А. М. Котов-Смоленский, Н. А. Супонева, М. А. Пирадов
}

Научный центр неврологии, Москва, Россия

По данным литературы, только 5-20\% пациентов после инсульта могут полностью восстановить двигательную функцию руки. Важны корректная постановка целей и индивидуальный подход, направленный на восстановление функционального статуса пациента. Целью исследования было на основании клинико-биомеханического анализа разработать алгоритм оценки нарушения двигательной функции руки у пациентов после инсульта и определить принципы выбора тактики реабилитации. В исследование были включены 25 пациентов с инсультом полушарной локализации и 10 здоровых добровольцев. Для оценки двигательной функции руки применяли формализованные клинические шкалы (шкала Фугл-Мейера, Эшворта, тест АRAT) и видеоанализ движений. Пациенты были разделены на 2 группы по степени тяжести пареза руки (легкий/умеренный и грубый/выраженный). В обеих группах проводили курс реабилитации, включавший механотерапию, массаж, ЛФК. Выявлено, что у пациентов 1-й группы восстановление двигательной функции в паретичной руке происходит по пути нормализации паттерна движения: нормализация биомеханических параметров, прямо коррелирующая с уменьшением клинической выраженности степени пареза по шкале Фугл-Мейера $(r=0,94 ; p=0,01)$. У пациентов 2-й группы восстановление двигательной функции в паретичной руке происходит по пути компенсации двигательного дефицита: сохранение патологической синергии по данным биомеханического анализа, обратно коррелирующее с уменьшением клинической выраженности степени пареза $(r=-0,9 ; p=0,03)$. В результате проведенного исследования сформирован алгоритм выбора тактики ведения пациентов, основанный на исходных клинических показателях.

Ключевые слова: инсульт, парез в руке, нейрореабилитация, адаптация, двигательное переобучение, биомеханика движений, видеоанализ движений, патологическая синергия

Финансирование: работа выполнена в рамках государственного заказа № 0512-2014-0036.

Информация о вкладе авторов: А. Е. Хижникова - планирование исследования, анализ литературы, сбор, анализ и интерпретация данных, подготовка черновика рукописи; А. С. Клочков - планирование исследования, анализ литературы, интерпретация данных, подготовка рукописи; А. М. Котов-Смоленский - проведение тренировок с пациентами, включенными в исследование, осмотр пациентов по клиническим шкалам; Н. А. Супонева — планирование исследования, интерпретация данных, подготовка рукописи; М. А. Пирадов — подготовка рукописи.

Соблюдение этических стандартов: исследование одобрено этическим комитетом ФГБНУ НЦН (протокол № 1-5/16 от 27 января 2016 г.). Все пациенть подписали добровольное информированное согласие на участие в исследовании.

$\measuredangle$ Для корреспонденции: Анастасия Евгеньевна Хижникова Волоколамское шоссе, д. 80, г. Москва, 125367; nastushkapal@gmail.com

Статья получена: 16.08.2019 Статья принята к печати: 30.08.2019 Опубликована онлайн: 31.08.2019

DOI: $10.24075 /$ vrgmu.2019.056

According to a number of authors, in the acute phase of a stroke, the hand paresis occurs in $48-77 \%$ of patients [1, 2]. At the same time, only $5-20 \%$ of patients are able to restore the motor function of the paretic arm completely by the end of the early recovery period $[3,4]$.
Restoration of the upper limb motor function consists of six consecutive stages (from flaccid paralysis to the ability to perform complex coordinated movements). However, the improvement can be completed at any stage, and the patient remains partially or completely lost self-care capabilities [5]. In 
this regard, an important condition for effective motor function restoration is to determine the tactics of patient rehabilitation to achieve the maximum effect, depending on the current stage.

It is known that in post-stroke patients with severe paresis and increased muscle tone the physiological movement pattern is impossible. As a consequence, prerequisites arise for the development of new motor synergies, which are inherently a compensatory mechanism. As a result, the body uses the remaining motor functions of the limb, or active movements in adjacent joints and functionally related kinematic chains to provide motion. The use of movements with a lower level of regulation as a part of compensatory synergies leads to a decrease in the adaptability to changing environmental conditions. Subsequently, compensatory synergies become pathological [6], which leads to a decrease in the patient's functional capabilities and a slowdown of further rehabilitation.

Nevertheless, it is worth noting that, according to some authors, compensation mechanisms are necessary for patients with severe paresis and the presence of these is important for the successful movement performance in post-stroke patients [7]. During the recovery process, the motor synergies manifest more comprehensively and become associated with spasticity and related reactions. Currently, the generally accepted view is that for better functional motor recovery it is necessary to conduct training within the existing pathological stereotype with the subsequent expansion of the active movement zone [8]. Thus, the restructuring of pathological synergy due to an increase in the number of "beneficial" motion components usually occurs during the training [9].

Correct goal setting and individual approach are important in developing a rehabilitation program aimed primarily at restoring the functional status of the patient. Video analysis of the paretic arm and shoulder girdle movements with a complex evaluation of inter-articular relationships and kinematic characteristics during rehabilitation can be invaluable in retrospective assessment of the recovery process. The study aimed to develop the principles of choosing the hand motor function restoration tactics in patients after a cerebrovascular accident on the basis of clinical and biomechanical analysis.

\section{METHODS}

The study was conducted on the basis of the Department of Neurorehabilitation and Physiotherapy of the Research Center of Neurology (2017-2018). Inclusion criteria: male and female patients aged 18-80; confirmed cerebrovascular accident of ischemic or hemorrhagic type; single lesion site of hemispheric localization which arose from 3 months to 2 years ago; poststroke hand paresis (grade 2-4 according to MRC Scale for Muscle Strength) [10]. Exclusion criteria: hand paresis grade according to MRC Scale for Muscle Strength less than 2; severe defect of deep sensitivity; neglect syndrome; muscle tone increase score exceeding 2 according to the Ashworth scale (score 0 corresponds to normal muscle tone); severe vision impairment not allowing to distinguish the image on the computer monitor; severe cognitive impairment which makes it difficult to execute the instructions; severe sensory or motor aphasia; left-handedness according to Edinburgh Handedness Inventory [11]. Twenty five patients with hemispheric cerebrovascular accident participated in the study. Among them, there were 17 men and 8 women aged 30-80 (median age 55 [45; 61]). The prescription of stroke was 3-23 months (median prescription of stroke was 7 months [4; 12]). Nine patients $(36 \%)$ were observed in the early recovery period, 9 patients (36\%) were observed in the late recovery period and 7 patients (28\%) were observed in the residual period. The study did not include patients with severe spasticity, gross speech and cognitive impairment, limiting the possibility of communication and following the instructions of the physical therapist.

To determine the normal kinematic pattern of hand movement, 10 healthy volunteers aged 24-42 (4 women and 6 men, right-handed, without pathologies of the musculoskeletal and nervous systems) were selected. For each subject, an analysis of movements was performed in both the dominant (right) and non-dominant (left) hands.

For clinical assessment of motor deficit, pathological synergies severity, reflex activity, surface and deep sensitivity, passive movement volume and pain sensation in the affected hands the Fugl-Meyer Assessment Scale was used [12]: the section for hand function evaluation (the maximum score for this section is normally 126). The Ashworth Scale was used for spasticity assessment in the paretic arm [13]. The wrist motor skills and functional movement were assessed using the ARAT test [14].

The 3D analysis of movements in patients was performed using the Biosoft-Videomotion 3D system (Biosoft; Russia). Since hand movements are very diverse and variable, the least variable parameter was chosen for the evaluation of biomechanical parameters: reaching an object (reaching test). Patients were seated at the table on a chair without a back, with armrests for both hands. Hands were placed on the armrests palms down (wrists were on the table). Within reach of each patient, a glass with a $10 \mathrm{~g}$ weigh was placed on the table. The patient was asked to reach the glass, take it, bring it to his mouth simulating the drinking process, then put the glass back and return the hand to its original position. If it was not possible to grasp the glass (severe hand paresis), the patient was asked to attempt to grasp it. To ensure the most automated movement, the patients were informed that the main objective of the study was to observe a drinking simulation movement. Thus, the reaching movement was performed with a minimum focus of attention, which made it possible to obtain automated action. Only the first part of the movement was measured (reaching a remotely located object).

To study intra-joint and inter-joint synergies in the sagittal and frontal planes, the following synergy coefficients $(C)$ were introduced: $\mathrm{C}_{1}$ - shoulder joint (SJ) flexion to SJ abduction ratio; $\mathrm{C}_{2}$ - elbow joint extension (EJ) to the SJ flexion ratio; $\mathrm{C}_{3}-\mathrm{EJ}$ extension to $\mathrm{SJ}$ abduction ratio.

During rehabilitation, the paretic hand functional skills training was performed using the mechanotherapeutic exoskeleton arm weight support Armeo Spring system (Hocoma; Switzerland), as well as training of bimanual and coordination movements controlled by the physical therapist and paretic hand massage. Rehabilitation was successful in all patients.

Statistical processing of the results was carried out using the Mann-Whitney test (independent samples), Wilcoxon signed ranks test (dependent samples), and Spearman's rank correlation coefficient on the personal computer using the Statsoft Statistica v. 7.0 software (StatSoft; USA). Data were presented as the median and $25 \%$ and $75 \%$ quartiles of the median. The differences were considered statistically significant at $p<0.05$.

\section{RESULTS}

\section{Clinical assessment}

During the comparative analysis of data according to the FuglMeyer Assessment Scale, a statistically significant increase in 
active movements in the shoulder, forearm, wrist and hand was observed in all patients after rehabilitation. A significant increase in the volume of passive movements in the elbow and wrist joints was also noted. It is important, that according to the Fugl-Meyer Assessment Scale, the pathological flexion synergy severity was significantly reduced (the higher the Fugl-Meyer Assessment score, the lower the degree of severity) (Table 1).

Statistical analysis of the Ashworth Scale score revealed that after rehabilitation the degree of spasticity in the elbow flexor muscles ( $p=0.00008$ ), wrist flexor muscles $(p=0.00098)$ and superficial flexor muscles of fingers $(p=0.0022)$ was significantly reduced. A decrease in spasticity in the studied muscle groups was observed in patients with a slight and mild muscle tone increase $(1 ; 1+)$ and in patients with a more pronounced muscle tone increase (2).

Clinical data analysis using the Fugl-Meyer Assessment Scale revealed a close relationship between the severity of pathological flexion synergy in the hand and the overall motor deficiency degree $(r=0.81 ; p=0.000000)$. According to the Fugl-Meyer Assessment score patients with severe paresis whose motor deficit was less than $50 \%$ of maximum active movement score (less than 33), patients with pronounced paresis - 50-70\% (34-46), patients with moderate paresis $71-89 \%(47-56)$ and patients with mild paresis - 90-99\% (57-65) were identified. For further analysis, patients were divided into 2 groups: group 1 - patients with mild/ moderate paresis, group 2 - patients with pronounced/ severe paresis.

A comparative analysis using some subsections of the Fugl-Meyer Assessment Scale showed that a significant improvement in the hand motor function occurred both in the proximal and distal parts of the hand in both subgroups (Table 2).

\section{Video analysis of the paretic hand movements while performing a reach test}

Analysis of the reach test time characteristics demonstrated that patients of both groups needed significantly more time to complete the target movement than a healthy person. In case of severe/pronounced paresis reaching a remotely located object needed significantly more time compared to normal $(p=0.001)$. The time difference between the group of healthy volunteers and the group of patients with mild/moderate paresis was less significant, it was only $0.55 \mathrm{~s}$ (Fig. 1).

Analysis of the reach test time characteristics after rehabilitation demonstrated that in the 1st group of patients (mild/moderate hand paresis) there was a statistically significant decrease in the time needed to reach the object $(p=0.04)$. In the 2nd group of patients (severe paresis) the time needed to complete the test, on the contrary, significantly increased $(p=0.043)$. It exceeded the corresponding normal indicator by more than 2 times.

Biomechanical research results analysis revealed that in patients with mild/moderate paresis the maximum angular amplitude of the shoulder joint flexion significantly reduced and the maximum angular amplitude of the shoulder joint abduction significantly increased while performing the reach test (Fig. 2A).

In addition to decreasing the maximum angle of movement of some joints in patients with mild/moderate paresis, the time needed to establish the maximum angular amplitude for all movements was increased compared to normal (Fig. 3A, C).

Kinematic pattern in the group of patients with severe/ pronounced paresis was different: when performing the movement, the maximum abduction angle of the shoulder joint was greater than normal (Fig. 2B). At the same time, the maximum extension angle of the elbow joint was significantly below normal (Fig. 3B, C)

Table 1. Median indicators (Me [25\%; 75\%]) of the hand motor impairment according to the Fugl-Meyer Assessment Scale subsections

\begin{tabular}{|l|c|c|}
\hline \multirow{2}{*}{ Scale section } & \multicolumn{2}{|c|}{ Group $(n=25)$} \\
\cline { 2 - 3 } & Before treatment & After treatment \\
\hline \multirow{2}{*}{ Total score } & $103[91 ; 109]$ & $109[99 ; 120]$ \\
\hline \multirow{2}{*}{ Shoulder and forearm movements } & \multirow{2}{*}{$29[24 ; 34]$} & $p=0.000025$ \\
\hline \multirow{2}{*}{ Wrist and hand movements } & \multirow{2}{*}{$18[13 ; 21]$} & $32[24 ; 38]$ \\
\hline \multirow{2}{*}{ Synergies } & \multirow{2}{*}{$9[6 ; 10]$} & $p=0.000821$ \\
\hline \multirow{2}{*}{ Passive movement amount } & \multirow{2}{*}{$21[20 ; 22]$} & $p=0.000168$ \\
\cline { 3 - 3 } & & $9.5[5 ; 11]$ \\
\cline { 3 - 3 } & & $p=0.000049$ \\
\hline
\end{tabular}

Table 2. Median indicators (Me [25\%; 75\%]) of the hand motor impairment according to the Fugl-Meyer Assessment Scale in patients before and after the rehabilitation

\begin{tabular}{|l|c|c|}
\hline \multicolumn{2}{|c|}{ Shoulder and forearm movements, score $(n=25)$} \\
\hline & Mild/moderate $(n=13)$ & Severe/pronounced $(n=12)$ \\
\hline Before treatment & $34[32 ; 37]$ & $24[21.5 ; 27]$ \\
\hline After treatment & $38[34 ; 41]$ & $30.5[25.5 ; 33.5]$ \\
\hline$p$-level & $p=0.041$ & $p=0.0068$ \\
\hline & Wrist and hand movements, score $(n=25)$ \\
\hline & Mild/moderate $(n=13)$ & Severe/pronounced $(n=12)$ \\
\hline Before treatment & $21[19 ; 21]$ & $12[8 ; 14.5]$ \\
\hline After treatment & $23[22 ; 24]$ & $14[10 ; 19.5]$ \\
\hline$p$-level & $p=0.0044$ & $p=0.012$ \\
\hline
\end{tabular}


In addition to some joints maximum angle reducing in patients with severe/pronounced paresis, the time needed to establish the maximum angular amplitude for all movements significantly increased compared to normal. In patients of this group, attention should be drawn to the change of time needed to reach the peak amplitude of the joint while moving. If in the group of patients with mild/moderate paresis the order of reaching maximum amplitudes of the joints remained the same, then in the group of patients with severe/pronounced paresis it was different. Thus, the abduction of the shoulder joint, which was the first of all joints to reach its peak both in healthy people and in patients with mild/moderate paresis, in patients with severe/pronounced paresis appeared only in the middle of the movement, after the extension of the wrist joint.

When comparing the maximum angular amplitudes of joints in the 1st group of patients before and after rehabilitation, no statistically significant differences were observed. At the same time, analysis of changes in the range of joint motion after training revealed significant changes in biomechanical parameters of the shoulder joint: the flexion amount increased $(p=0.04)$ and the abduction amount decreased $(p=0.01)$.

Analysis of the movement velocity parameters changes demonstrated a significant increase in the angular velocity of the shoulder joint flexion $(p=0.01)$, the elbow joint extension $(p=0.02)$, as well as a decrease in the angular velocity of the shoulder joint abduction ( $p=0.02$ ). When studying synergy coefficients reflecting inter-joint interactions in the $1^{\text {st }}$ group of patients, significant differences after rehabilitation were revealed only by the $\mathrm{C}_{2}$ coefficient $(p=0.04)$ reflecting the interaction between the shoulder joint flexion and the elbow joint extension during the reach test execution.

When comparing the maximum angular amplitudes of the joints in the $2^{\text {nd }}$ group of patients (severe/pronounced paresis) before and after rehabilitation, a significant decrease in the maximum extension angle of the elbow joint was revealed $(p=0.01)$. No significant changes in other joints were noted.

When analyzing the range of motion of the joints in the second group of patients, changes were observed that were opposite to those obtained in patients of the first group. During rehabilitation the shoulder joint flexion significantly reduced ( $p=0.02$ ), a significant increase of the shoulder joint abduction was also observed $(p=0.04)$. No significant differences were found in the elbow joint before and after rehabilitation. It is also worth noting that, despite a decrease in the shoulder joint flexion, statistically significant differences in this indicator from normal values were not found.

Significant differences in the amount of movements from the normal motor stereotype persisted in other indicators: shoulder joint abduction amount $(p=0.04)$, elbow joint extension amount $(p=0.007)$, wrist joint extension amount $(p=0.02)$. In addition, the opposite changes in the movement velocity characteristics in the $2^{\text {nd }}$ group patients were revealed compared to changes in patients of the first group. Thus, after rehabilitation, a significant increase in the angular velocity of the shoulder joint abduction was noted $(p=0.02)$, at the same time, a significant decrease in the angular velocity $(p=0.02)$ occurred in the elbow joint while reducing the extension and maximum angular amplitude. When studying synergy coefficients reflecting inter-articular interactions in patients of the second group, the significant differences after rehabilitation were observed only by the $C_{2}$ coefficient, which significantly decreased $(p=0.04)$ after training.

\section{Analysis of the shoulder girdle movement biomechanics while performing the reach test}

Despite the fact that the study results demonstrated that there was no effect of training on the severity of pathological synergy

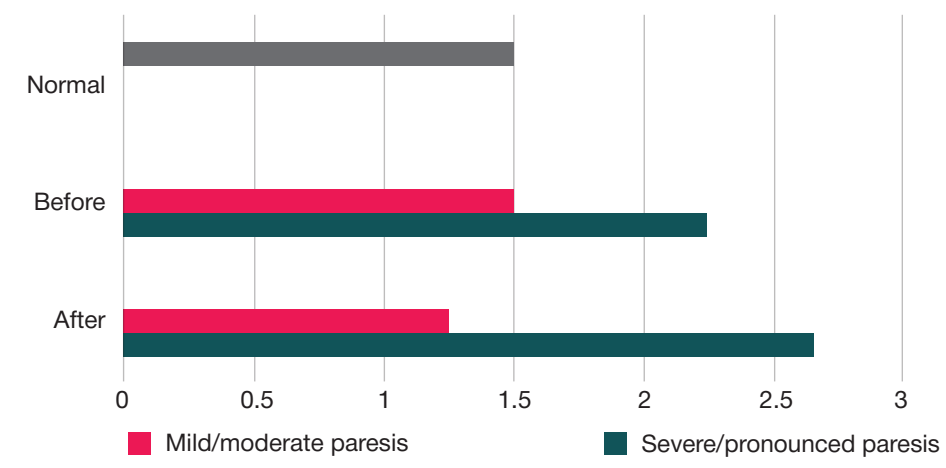

Fig. 1. Time (s) needed to complete the reach movement $n$ patients with varying degrees of hand paresis

A

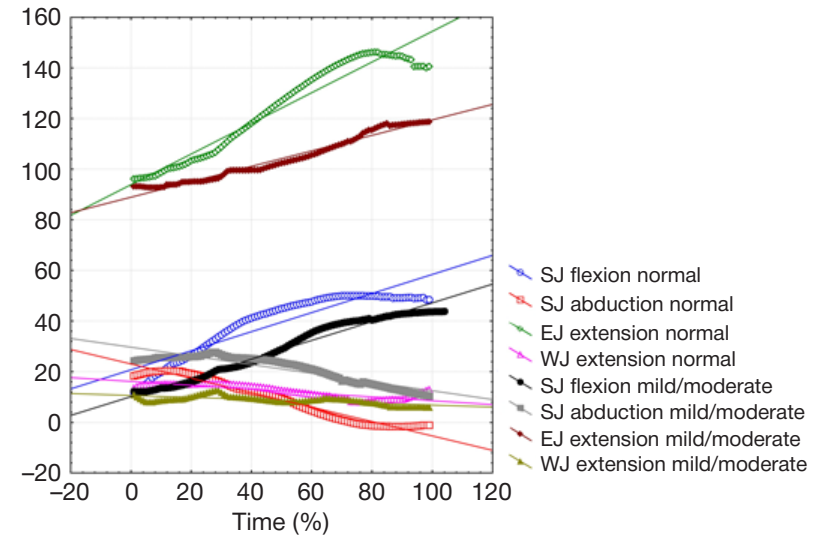

B

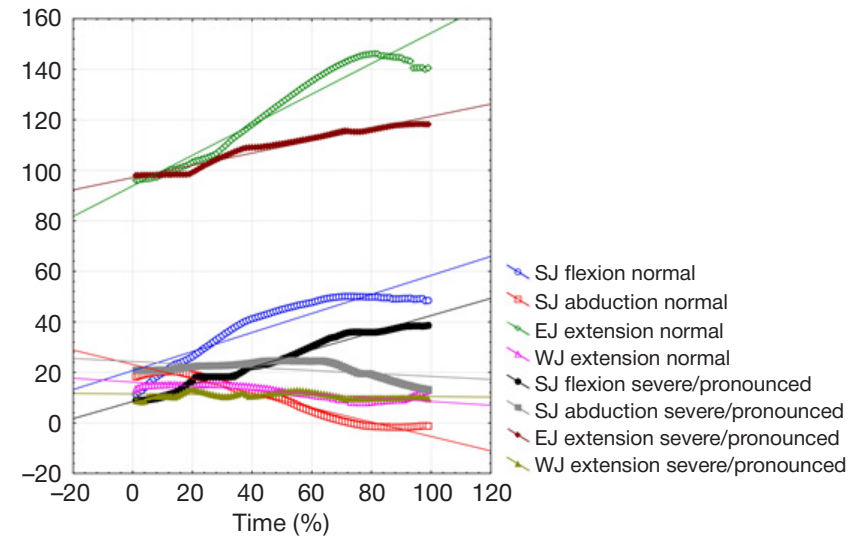

Fig. 2. The paretic hand inter-articular interactions in patients with mild/moderate $(\mathbf{A})$ and severe/pronounced (B) paresis 
in patients with severe/pronounced hand paresis, the clinical assessment showed an improvement of functional capabilities in the paretic hand, which was expressed as a significant improvement of fine motor skills confirmed by the ARAT test. In some studies, a decrease in the displacement of the body and shoulder girdle was observed during the video analysis of movements in patients with moderate paresis having the improved functionality according to clinical scales $[15,16]$. To confirm the hypothesis of the shoulder girdle compensatory movement in patients with severe/pronounced hand paresis the additional movement analysis was carried while performing the reach test. For this purpose, the displacement of two markers located on the acromion of the healthy and paretic shoulders in the frontal plane was evaluated.

The results demonstrated a shoulder girdle displacement towards the object in patients with severe/pronounced paresis when performing the reach test before training (23 [19.8; 57.4] healthy shoulder; 169 [88.0; 178.0] - paretic shoulder) as well as after training (66 [49.0; 81.0] — healthy shoulder; 215 [162.0; 229.0] — paretic shoulder) with significantly greater prevalence of paretic shoulder displacement. In addition, the analysis revealed a significant $(p=0.04)$ increase in the shoulder girdle forward displacement when performing a reach movement during rehabilitation.

\section{DISCUSSION}

After rehabilitation, the data was obtained that both groups of patients not only differ significantly in their kinematic pattern, but also have different ways of motor function recovery.

Thus, in patients with mild/moderate paresis, the motor function restoration in the paretic hand was due to movement performance recovery which was evidenced by an increase in the $\mathrm{C}_{2}$ coefficient, reflecting the inter-articular interaction in the

A

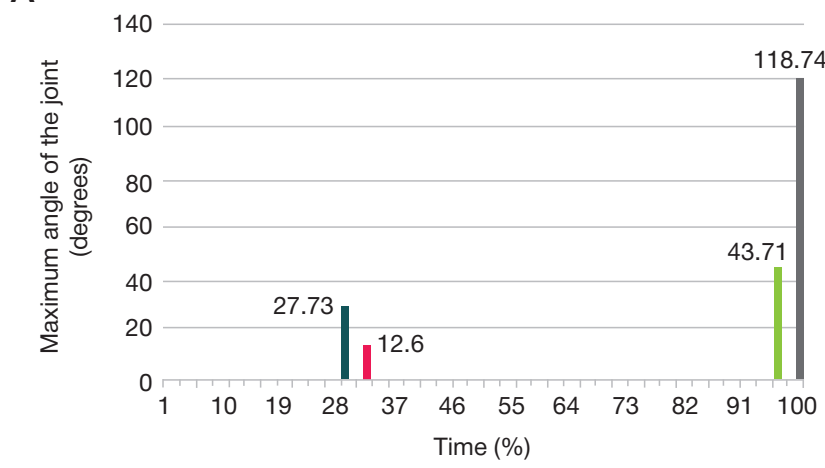

shoulder and elbow joints. The latter directly correlated with a decrease in the paresis degree according to the Fugl-Meyer Assessment Scale $(r=0.94 ; p=0.01)$. In patients with severe/ pronounced hand paresis the motor function recovery in the paretic hand was due to motor deficit compensation which was evidenced by decrease in the $\mathrm{C}_{2}$ coefficient. The latter inversely correlated with a decrease in the paresis degree according to the Fugl-Meyer Assessment Scale ( $r=-0.9 ; p=0.03$ ), i.e. in said patients the functional hand movement improved while maintaining a pathological pattern of movement. Further analysis showed that in patients with severe/pronounced paresis the shoulder girdle forward shift significantly increased after rehabilitation while performing the reaching test. During the correlation analysis, a negative relationship between the marker displacement in the paretic shoulder and the $C_{2}$ value was found ( $r=-0.9 ; p=0.03$ ). Relationship between the trunk and paretic limb movements is also noted in a number of studies [17]. These data indicate the presence of a compensatory mechanism in patients with severe/pronounced paresis and explain the decrease in this coefficient after rehabilitation since the larger is the body displacement, the less are the range of motion and maximum angles of the joints. It can be assumed that in patients with severe/pronounced paresis the motor skills recovery is due to compensation, therefore, it is impossible to return to the normal pattern of movements for patients with fully developed pathological hand synergy. According to our data, the training carried out by a rehabilitation specialist should not always be aimed at overcoming pathological synergies, since it is advisable to use compensatory mechanisms as efficiently as possible to adapt and train patients with severe/pronounced paresis. This conclusion was also confirmed by clinical examination data analysis, since after rehabilitation a significant improvement in the functionality of the paretic arm was noted

B

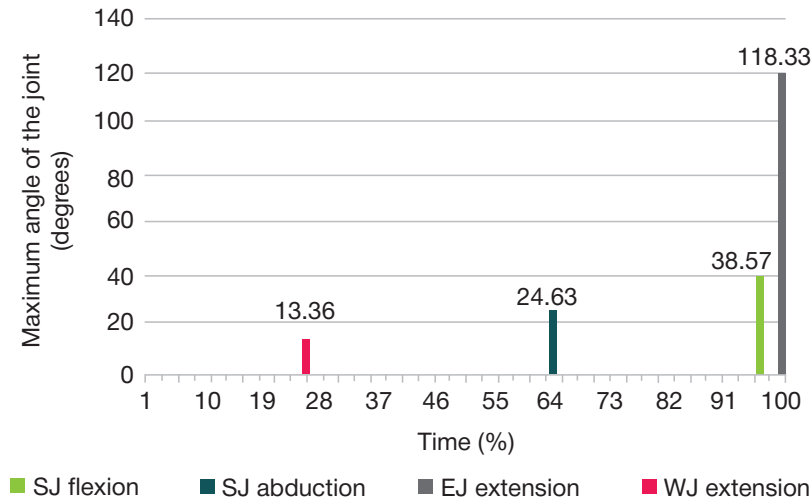

- SJ flexion $\quad$ SJ abduction EJ extension $\quad$ WJ extension

C

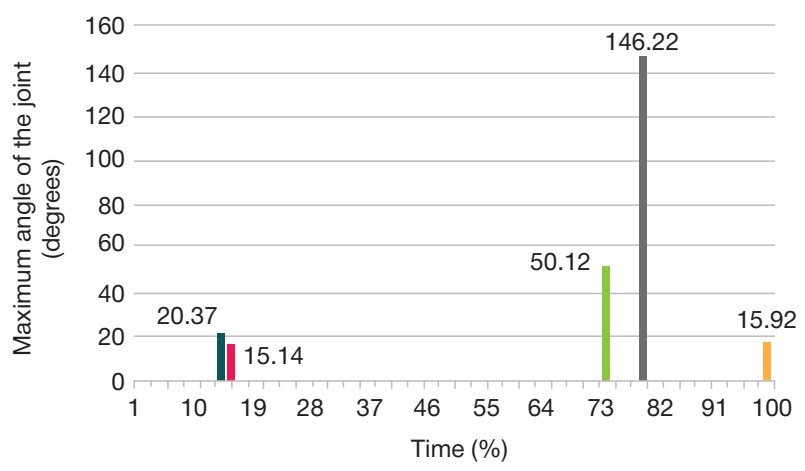

SJ flexion

SJ abduction

EJ extension

WJ extension

WJ extension

Fig. 3. The maximum angular amplitude of different joints while performing the reach test in healthy people (A) and in patients with mild/moderate paresis (B) compared to normal (C) 


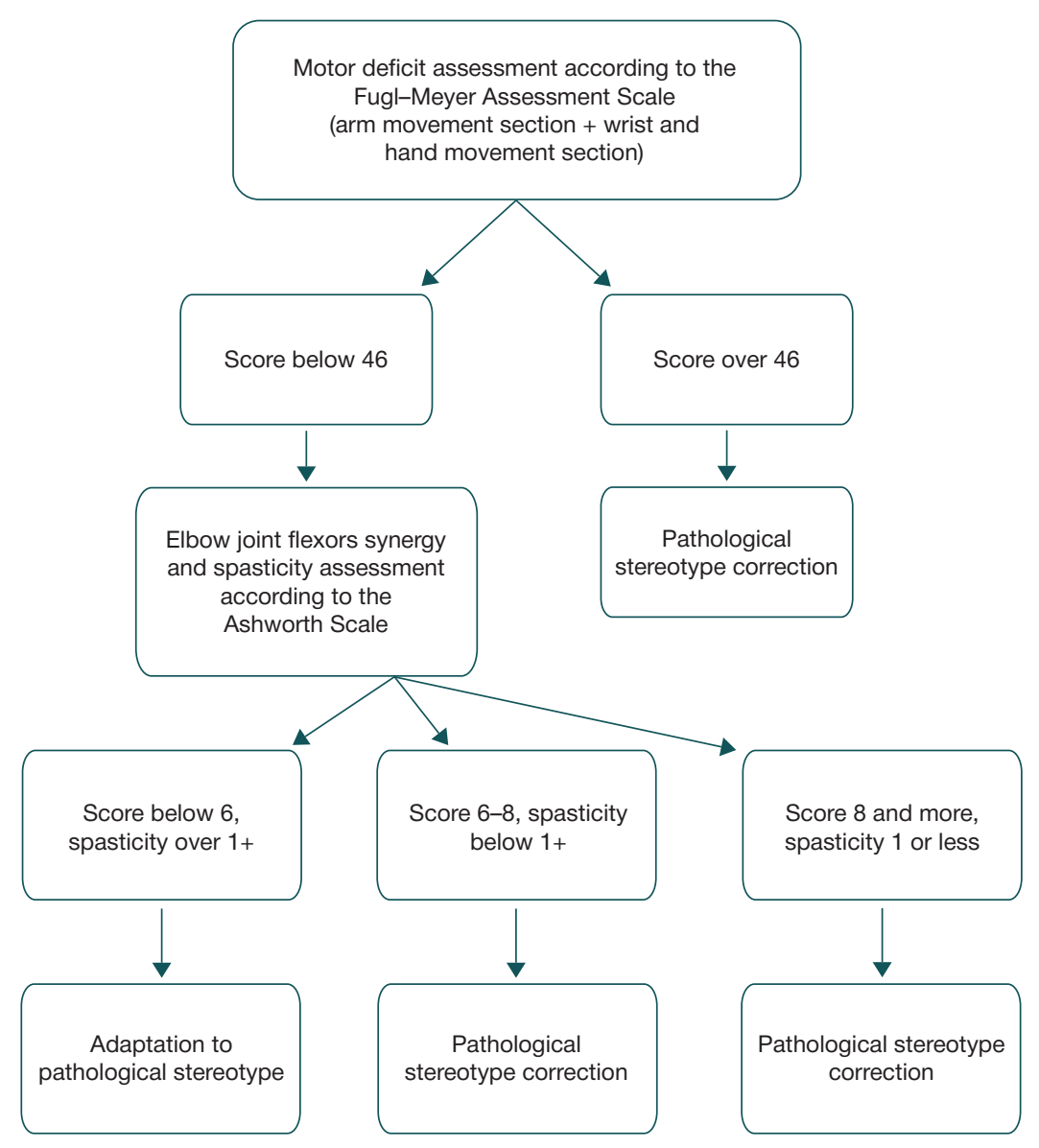

Fig. 4. Algorithm for choosing tactics of rehabilitation in patients with post-stroke hand paresis

in both groups of patients, in particular, their fine motor skills improved. We assume, and this is comparable with the data of many studies [18-21], that this effect may be associated with the restriction absence of axis in the paretic limb during training, as the patients are trained to act within their stereotype and overcome it arbitrarily if necessary.

Based on the obtained clinical biomechanical data for the groups of patients with different spasticity degree and hand paresis severity, the algorithm of rehabilitation tactics choosing was determined for patients with post-stroke hand paresis (Fig. 4). In this case, an assessment before the start of the rehabilitation and the rehabilitation strategy development should be carried out according to the subsection of the Fugl-Meyer Assessment Scale for the upper limb. It is worth noting that an assessment according to the Ashworth Scale is also necessary and should be carried out in three muscle groups: elbow and wrist joints flexors and flexors of the fingers. The spasticity degree which affects the patient management tactics choice in two or more muscle groups is $1+$.

\section{References}

1. Lawrence ES, Coshall C, Dundas R, et al. Estimates of the prevalence of acute stroke impairments and disability in a multiethnic population. J Stroke. 2001; (32): 1279-84.

2. Persson HC, Parziali M, Danielsson A, Sunnerhagen KS. Outcome and upper extremity function within 72 hours after first occasion of stroke in an unselected population at a stroke unit. A part of the SALGOT study. J BMC Neurol. 2012; (12): 162.

\section{CONCLUSIONS}

The detailed clinical biomechanical study of the kinematic pattern change dynamics for one of the most functionally significant human movements (reach test) during rehabilitation demonstrated that the baseline lesion severity and spasticity degree are crucial for the most effective and successful restoration of the paretic hand function. These are responsible for the formation of pathological motor synergies in patients with post-stroke hand paresis and for activation of various mechanisms of the motor stereotype transformation during the recovery process. The data obtained made it possible to determine an algorithm for choosing the rehabilitation tactics based primarily on clinical indicators: in patients with mild/moderate paresis it is useful to conduct training within the physiological movement pattern aimed at correcting the pathological stereotype together with the suppression of compensatory mechanisms; on the contrary, patients with severe/pronounced hand paresis need training with the promotion of compensation mechanisms and an increase in the functionality of the paretic hand within the previously formed pathological stereotype. 
6. Santello M, Lang CE. Are movement disorders and sensorimotor injuries pathologic synergies? When normal multi-joint movement synergies become pathologic. J Front Hum Neurosci. 2015; (8): 1050

7. van Kordelaar J, van Wegen EE, Kwakkel G. Unraveling the interaction between pathological upper limb synergies and compensatory trunk movements during reach-to-grasp after stroke: a cross-sectional study. J Exp Brain Res. 2012; 221 (3): 251-62.

8. Van Vliet PM, Sheridan MR. Coordination between reaching and grasping in patients with hemiparesis and healthy subjects. J Arch Phys Med Rehabil. 2007; (88): 1325-31.

9. Hogan L, Dipietro HI, Krebs SE, et al. Changing Motor Synergies in Chronic Stroke. J Neurophysiol. 2007; (98): 757-68.

10. Compston $\mathrm{A}$. Aids to the investigation of peripheral nerve injuries. Medical Research Council: Nerve Injuries Research Committee. His Majesty's Stationery Office: 1942; pp. 48 (iii) and 74 figures and 7 diagrams; with aids to the examination of the periphera nervous system. By Michael O'Brien for the Guarantors of Brain. Saunders Elsevier. Brain. 2010; 133 (10): 2838-44.

11. Oldfield RC. The assessment and analysis of handedness: the Edinburgh inventory. Neuropsychologia. 1971; (9): 97-113.

12. Sanford J, Moreland J, Swanson LR, Stratford PW. Reliability of the Fugl-Meyer assessment for testing motor performance in patients following stroke. J Gowland C Phys Ther. 1993; 73 (7): 447-54.

13. Bohannon RW, Smith MB. Interrater reliability of a modified Ashworth scale of muscle spasticity. J Phys Ther. 1987; 67 (2): 206-7.

14. Doussoulin SA, Rivas SR, Campos SV. Validation of «Action

\section{Литература}

1. Lawrence ES, Coshall C, Dundas R, et al. Estimates of the prevalence of acute stroke impairments and disability in a multiethnic population. J Stroke. 2001; (32): 1279-84.

2. Persson HC, Parziali M, Danielsson A, Sunnerhagen KS. Outcome and upper extremity function within 72 hours after first occasion of stroke in an unselected population at a stroke unit. A part of the SALGOT study. J BMC Neurol. 2012; (12): 162.

3. Langhorne P, Coupar F, Pollock A. Motor recovery after stroke: a systematic review. Lancet Neurol. 2009; 8 (8): 741-54.

4. Veerbeek JM, Kwakkel G, van Wegen EE, Ket JC, Heymans MW. Early prediction of outcome of activities of daily living after stroke: a systematic review. Stroke. 2011; 42 (5): 1482-8.

5. Brunnstrom S. Movement Therapy in Hemiplegia: A Neurophysiological Approach. Facts and Comparisons. NewYork: Harper and Row, 1970

6. Santello M, Lang CE. Are movement disorders and sensorimotor injuries pathologic synergies? When normal multi-joint movement synergies become pathologic. J Front Hum Neurosci. 2015; (8): 1050

7. van Kordelaar J, van Wegen EE, Kwakkel G. Unraveling the interaction between pathological upper limb synergies and compensatory trunk movements during reach-to-grasp after stroke: a cross-sectional study. J Exp Brain Res. 2012; 221 (3): 251-62.

8. Van Vliet PM, Sheridan MR. Coordination between reaching and grasping in patients with hemiparesis and healthy subjects. J Arch Phys Med Rehabil. 2007; (88): 1325-31.

9. Hogan L, Dipietro HI, Krebs SE, et al. Changing Motor Synergies in Chronic Stroke. J Neurophysiol. 2007; (98): 757-68.

10. Compston A. Aids to the investigation of peripheral nerve injuries. Medical Research Council: Nerve Injuries Research Committee. His Majesty's Stationery Office: 1942; pp. 48 (iii) and 74 figures and 7 diagrams; with aids to the examination of the periphera nervous system. By Michael O'Brien for the Guarantors of Brain. Saunders Elsevier. Brain. 2010; 133 (10): 2838-44.

11. Oldfield RC. The assessment and analysis of handedness: the Edinburgh inventory. Neuropsychologia. 1971; (9): 97-113.

12. Sanford J, Moreland J, Swanson LR, Stratford PW. Reliability
Research Arm Test» (ARAT) in Chilean patients with a paretic upper limb after a stroke. Rev Med Chil. 2012; 140 (1): 59-65.

15. Alt Murphy M, Willén C, Sunnerhagen KS. Movement kinematics during a drinking task are associated with the activity capacity level after stroke. J Neurorehabil Neural Repair. 2012; 26 (9): 1106-15.

16. Valdés BA, Glegg SMN, Van der Loos HFM. Trunk Compensation During Bimanual Reaching at Different Heights by Healthy and Hemiparetic Adults. J Mot Behav. 2017; 49 (5): 580-92.

17. van Kordelaar J, van Wegen EE, Kwakkel G. Unraveling the interaction between pathological upper limb synergies and compensatory trunk movements during reach-to-grasp after stroke: a cross-sectional study. J Exp Brain Res. 2012; 221 (3): 251-62.

18. Roh J, Rymer WZ, Perreault EJ, et al. Saturated muscle activation contributes to compensatory reaching strategies after stroke. $J$ Neurophysiol. 2013; 109 (3): 768-81.

19. Basteris A, Nijenhuis SM, Stienen AH, et al. Training modalities in robot-mediated upper limb rehabilitation in stroke: a framework for classification based on a systematic review. J Neuroeng Rehabil. 2014; 10 (11): 111.

20. Daunoraviciene K, Adomaviciene A, Grigonyte A, Griškevičius J, Juocevicius A. Effects of robot-assisted training on upper limb functional recovery during the rehabilitation of poststroke patients. J Technol Health Care. 2018; 26 (2): 533-42.

21. Ustinova KI, Chernikova LA, Khizhnikova AE, Poydasheva AG, Suponeva NA, Piradov MA. Theoretical basis for classical methods of motor rehabilitation in neurology. Annals of clinical and experimental neurology. 2018; 12 (3): 54-60.

of the Fugl-Meyer assessment for testing motor performance in patients following stroke. J Gowland C Phys Ther. 1993; 73 (7): 447-54.

13. Bohannon RW, Smith MB. Interrater reliability of a modified Ashworth scale of muscle spasticity. J Phys Ther. 1987; 67 (2): 206-7.

14. Doussoulin SA, Rivas SR, Campos SV. Validation of «Action Research Arm Test" (ARAT) in Chilean patients with a paretic upper limb after a stroke. Rev Med Chil. 2012; 140 (1): 59-65.

15. Alt Murphy M, Willén $C$, Sunnerhagen KS. Movement kinematics during a drinking task are associated with the activity capacity level after stroke. J Neurorehabil Neural Repair. 2012; 26 (9): 1106-15.

16. Valdés BA, Glegg SMN, Van der Loos HFM. Trunk Compensation During Bimanual Reaching at Different Heights by Healthy and Hemiparetic Adults. J Mot Behav. 2017; 49 (5): 580-92.

17. van Kordelaar J, van Wegen EE, Kwakkel G. Unraveling the interaction between pathological upper limb synergies and compensatory trunk movements during reach-to-grasp after stroke: a cross-sectional study. J Exp Brain Res. 2012; 221 (3): 251-62.

18. Roh J, Rymer WZ, Perreault EJ, et al. Saturated muscle activation contributes to compensatory reaching strategies after stroke. J Neurophysiol. 2013; 109 (3): 768-81.

19. Basteris A, Nijenhuis SM, Stienen AH, et al. Training modalities in robot-mediated upper limb rehabilitation in stroke: a framework for classification based on a systematic review. J Neuroeng Rehabil. 2014; 10 (11): 111.

20. Daunoraviciene K, Adomaviciene A, Grigonyte A, Griškevičius J, Juocevicius A. Effects of robot-assisted training on upper limb functional recovery during the rehabilitation of poststroke patients. J Technol Health Care. 2018; 26 (2): 533-42.

21. Устинова К. И., Черникова Л. А., Хижникова А. Е., Пойдашева А. Г., Супонева Н. А., Пирадов М. А. Теоретическое обоснование классических методов двигательной реабилитации в неврологии. Анналы клинической и экспериментальной неврологии. 2018; 12 (3): 54-60. 